\title{
An Intelligent Color Image Recognition and Mobile Control System for Robotic Arm
}

\author{
Albert Wen Long Yao ${ }^{\mathrm{a}, 1, *}$, H. C. Chen ${ }^{\mathrm{b}, 2}$ \\ ${ }^{a}$ Department of Mechatronics Engineering, National Kaohsiung University of Science and Technology, Distinguished \\ Professor, Kaohsiung City, Taiwan \\ ${ }^{b}$ Department of Mechatronics Engineering, National Kaohsiung University of Science and Technology, Graduate \\ Student, Kaohsiung City, Taiwan \\ ${ }^{1}$ yao.nkfust@gmail.com; ${ }^{2}$ F107102120@nkust.edu.tw \\ * Corresponding Author
}

\section{ARTICLE INFO}

\section{Article history}

Received January 02, 2022

Revised February 07, 2022

Accepted February 11, 2022

\section{Keywords}

Color Image Recognition;

Web database

Mobile control system

\begin{abstract}
The aim of this study is to develop intelligent color recognition, mobile control, and monitoring system for a pick-and-place robotic arm for manufacturing systems. The demand for smart manufacturing factories with real-time control of fabricating processes and traceability of production information is increasing urgently. Generally speaking, a smart manufacturing facility is usually composed of sensing, computing, control, and communication technologies together. In this study, the three-tier architecture of the Internet of things (IoT) was adopted as a guideline to design mobile devices to control and monitor a color image recognition and alarm monitoring system by using Raspberry Pi and a web page database. The practical results and contributions of this study are as follows: With integrating the techniques of advanced B\&R PLC, mobile devices and APP, color image recognition, Raspberry Pi microcomputer, and MySQL database technologies together, (1) the mobile control and monitoring system is able to supervise a real-time manufacturing plant anywhere and anytime with mobile devices easily; (2) the color identification system can identify and classify different color work-piece precisely, and the identification results are recorded for remote database platform; (3) the collected data are analyzed and displayed on mobile devices through the web database for field operators and engineers promptly. It provides a very successful practical paradigm to promote conventional factories to meet industry 4.0.
\end{abstract}

This is an open-access article under the CC-BY-SA license.

\section{Introduction}

Under the trend of industry 4.0, the manufacturing industry is facing the issue of transformation. A manufacturing facility is necessary to integrate physical equipment, sensors, and communication technology through the virtual and real system [1-6]. In order to achieve the cooperation of humans and machines, the factory is expected to drive the improvement of efficiency and flexibility of the manufacturing process. Because of the lack of workforces, the enterprise also urgently needs to promote traditional manufacturing plants to a smart manufacturing factory [7-18]. The traditional manufacturing plant needs to capture, monitor, and analyze the status and operation data of the facility in real-time to meet the demand of managing production and predictive maintenance [19-24]. 
Moreover, sensing, computing, control, and communication technologies are required to form up a smart production system [25-27]. The data of status and information of production facility are needed to collect and calculate statistically to provide prompt fabricating information to the operator and engineer/manage staff [28-30].

The following techniques are employed in this study: (1) image processing and identification technology of Raspberry Pi, (2) remote web database technology of MySQL, and (3) monitoring and alarm technology of the mobile device. Fig. 1 shows the proposed systematical diagram of this study based on the principle of the three-tier architecture of IoT. It well explains the related technologies and system construction of color image identification technology and remote database web technology, respectively. Fig. 2 depicts the hardware connection for the web database system.

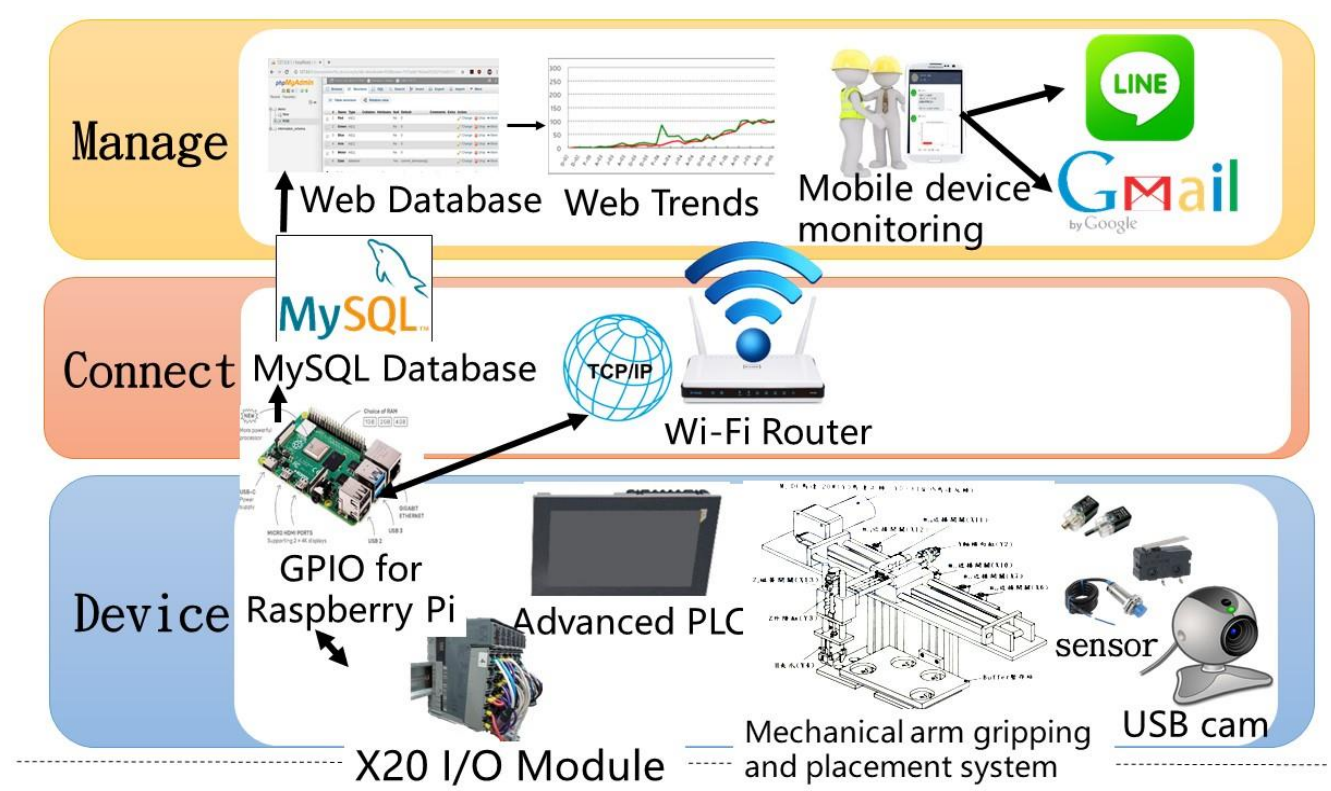

Fig. 1. A three-tier based system architecture of IoT.

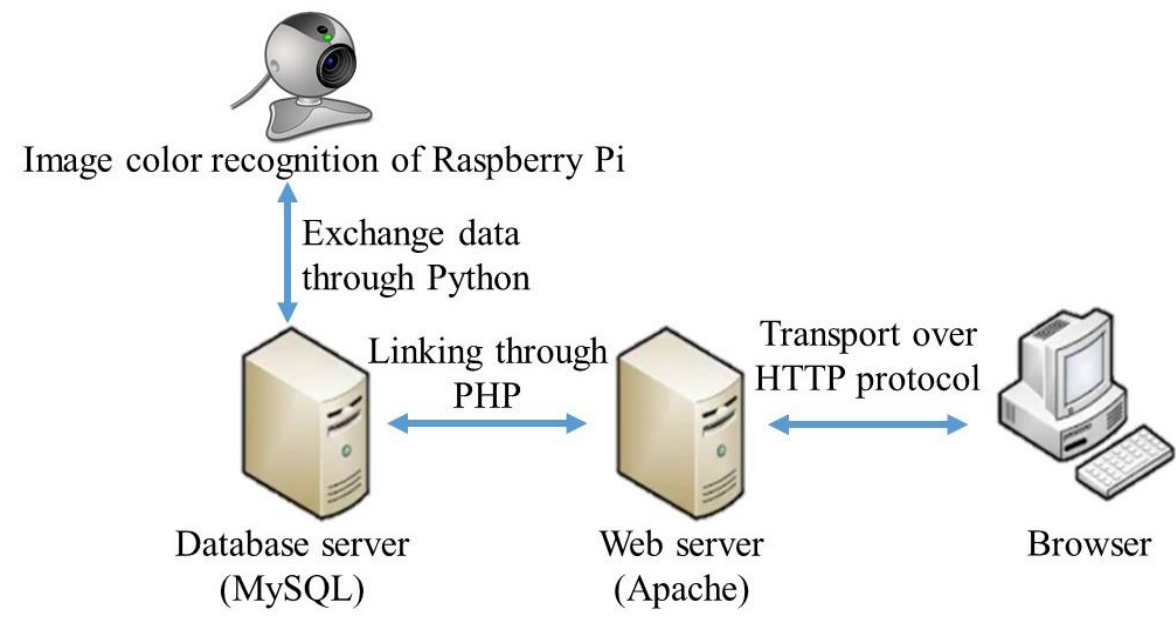

Fig. 2. Hardware connection for Web Database System

\section{Method}

In this study, an advanced B\&R PLC and Raspberry Pi microcomputer are employed to carry out the tasks of online real-time monitoring and alarm and color image identification. It provides more competitive and flexible functions for intelligent automatic control system applications. Fig. 3 shows the configuration layout of the system. Fig. 4 illustrates the robot arm for the manufacturing system. 
Among them, image processing and identification technology of Raspberry Pi mainly employ USB cam to capture images and store them in Raspberry Pi then converts the image RGB color format into HSV color format, and then carries out the binarization of OpenCV and shape processing for color recognition, and the remote web database technology of MySQL collects data through GPIO pinout of Raspberry Pi and records the data in the MySQL. Fig. 5 and Fig. 6 show the LINE notification Python code and Gmail Python code for sending messages, respectively. These programs are mainly used to trigger the GPIO pin of Raspberry Pi to record down the data when the device exception condition is reached, and then send out a prompt message to users.

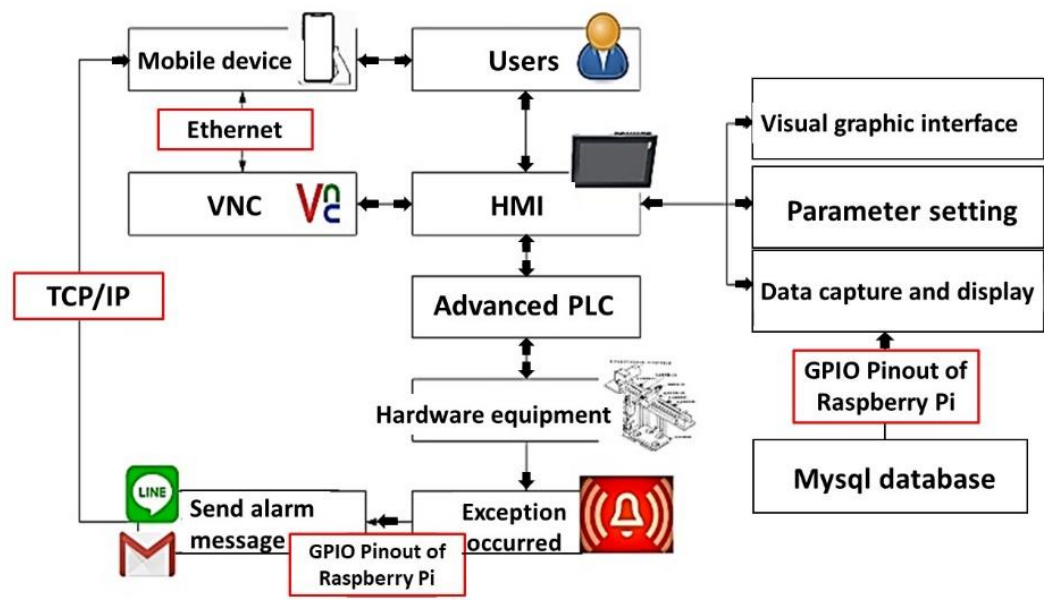

Fig. 3. System configuration.

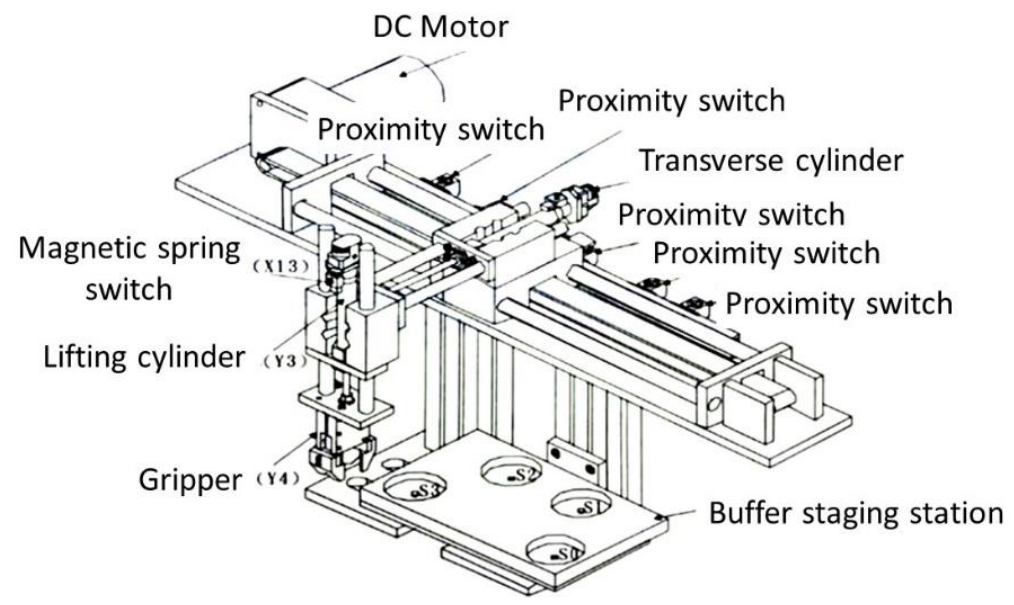

Fig. 4. Robot arm for the manufacturing process.

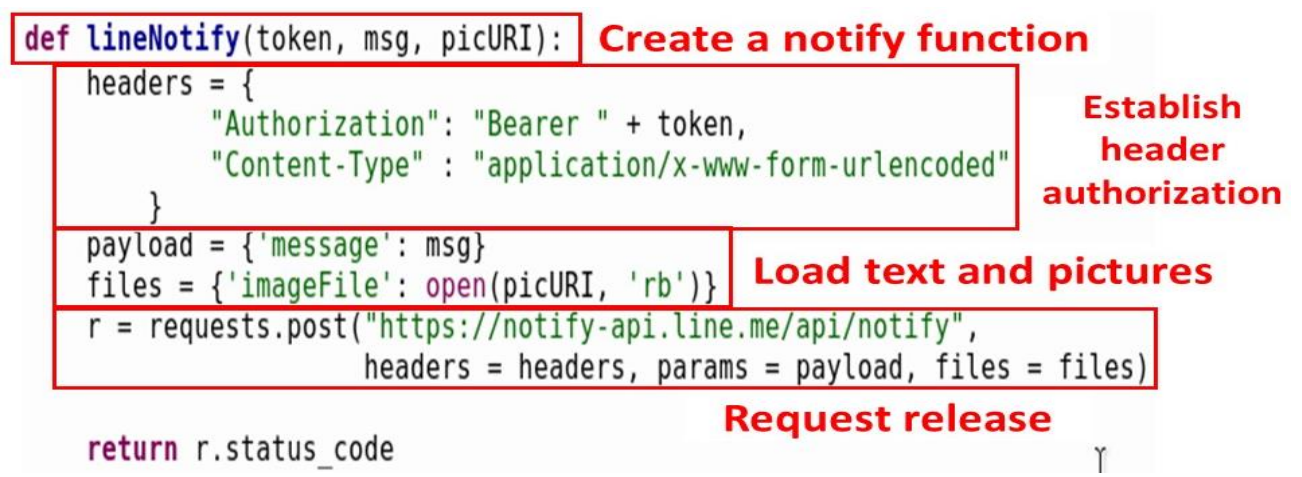

Fig. 5. Python code of LINE notification. 

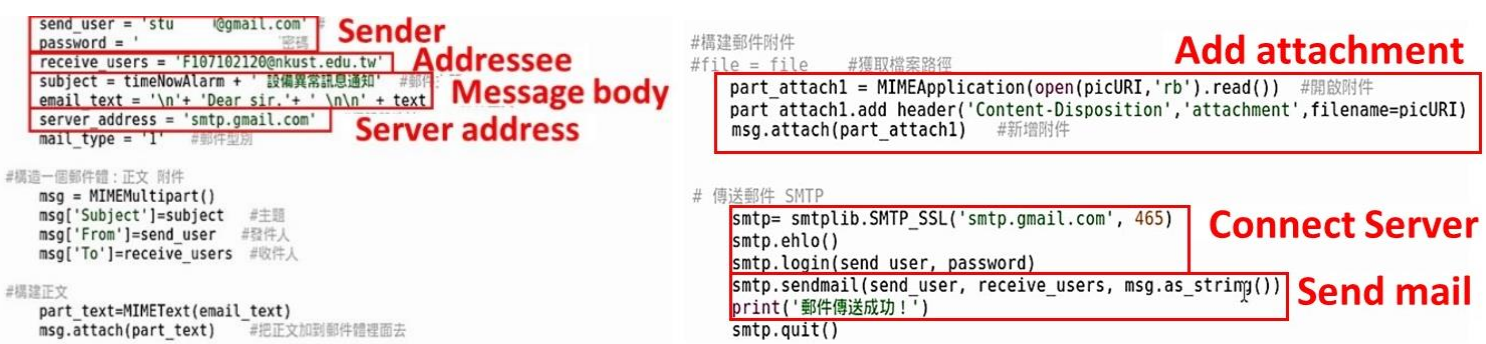

Fig. 6. Python code of Gmail notification.

\section{Results and Discussion}

In the mobile monitoring and alarm function, the main screen displays the basic operational information of the process, such as the position of the robot arm, work piece in place, the status of sensors, start button, emergency stop button, and screen page change button. In Fig. 7, the real-time synchronous operation is displayed on both the on-site man-machine interface (HMI) screens and mobile devices simultaneously. In Fig. 8, the system will send alarm messages to the line app of the user group and email on mobile devices, respectively. The line group and the specific mailbox will receive the notification of the alarm messages at the same time the malfunction of the manufacturing process occurs.

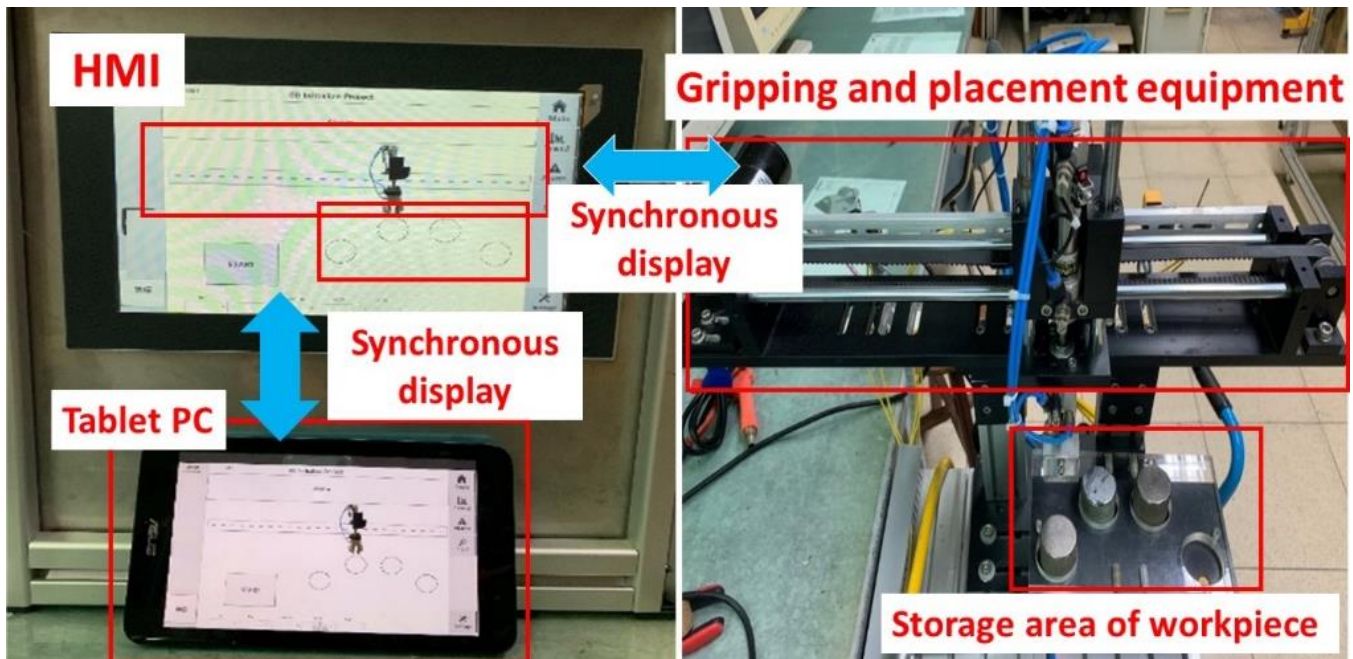

Fig. 7. Real-time synchronous operation display on both HMI and mobile device.

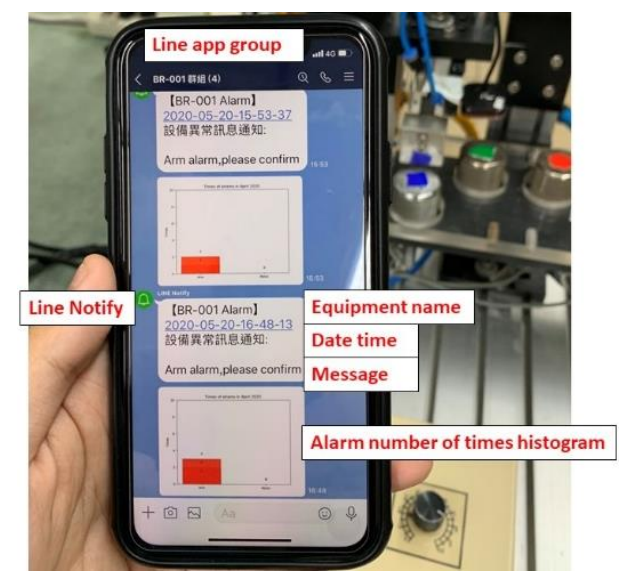

Fig. 8. Real-time line app group fault message notification.

The USB camera is installed next to the robotic arm. It will recognize the image of different colors immediately when the arm lowers down toward the work piece, and the pick-and-place arm will clamp 
the work piece to the correct position. The color image identification system shows the color ID of work piece to facilitate the camera for recognizing the color image. The identified work piece was labeled with three colors red, green, and blue. In Fig. 9, after the color recognition teaching procedure is performed first, then the work piece is randomly placed in the feeder, the result of color identification is sent to the HMI and flat panel display.

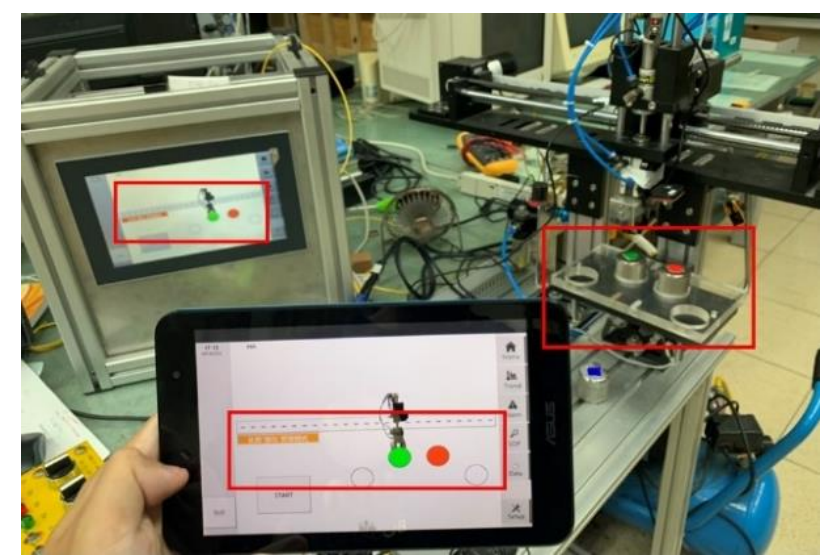

Fig. 9. The color identification system and its operation result are displayed on the HMI and flat-panel, respectively.

The acquisition of operational data is acquired to the database platform via the Python of Raspberry Pi computer. It provides real-time query of web platform after stacking. Fig. 10 and Fig. 11 show the data format and the display of real-time production information for web browser and MySQL database on the web pages, respectively.

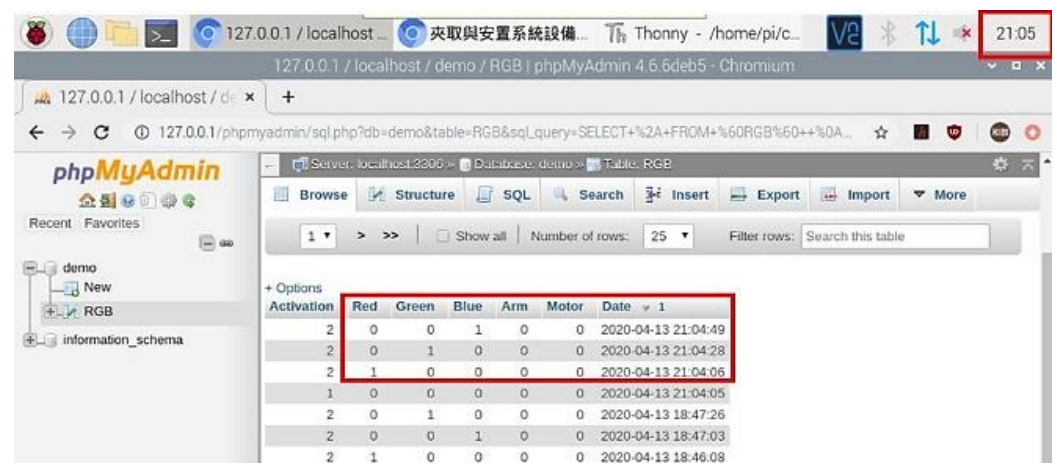

Fig. 10. MySQL database of recorded data.

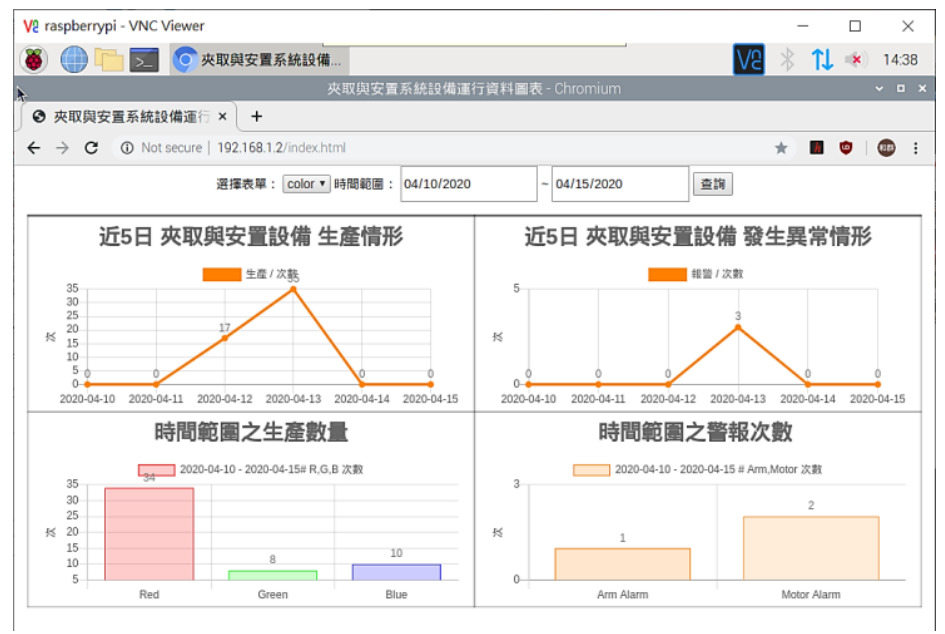

Fig. 11. Remote web page of production status. 


\section{Conclusions}

In this study, a color image identification and monitoring and alarm system for a pick-and-place robot arm of manufacturing system were developed successfully. It integrates the advanced PLC, Raspberry Pi microcomputer, and MySQL database technologies together. It includes the system integration of hardware and software programming of PLC\&HMI, MySQL database, line app, and Gmail of mobile devices configuration. The mobile control and monitoring function can supervise the status and malfunction information of the factory via the user group line app and email concurrently. In addition, it also provides remote connection of HMI and mobile devices through the VNC software for remote control and monitoring the fabrication facility. The functions of color image recognition and remote web page database can identify the color ID of work piece with USB camera, and the operational results were recorded and sent to the remote MySQL-based data acquisition system, and then generate information charts on the web page screen which provides information of maintenance and operation to operators and engineers. The novelty of this proposed system is adopting open-shelve equipment and tools, such as the advanced B\&R PLC, USB camera, Raspberry Pi microcomputer, and MySQL database technologies together. It can easily promote a conventional factory to an intelligent one to improve the efficiency and feasibility of the manufacturing facility for Industry 4.0. The future works are as follows: (1) The image recognition function can be added with the shape, size, or bar code of work pieces, so as to bring more image recognition and more diversities of production processes; (2) The acquired information of the manufacturing plant can use to analyze and generate more useful fabrication intelligence for later smart manufacturing application.

Author Contribution: All authors contributed equally to the main contributor to this paper. All authors read and approved the final paper.

Funding: This research received no external funding.

Conflicts of Interest: The authors declare no conflict of interest.

\section{References}

[1] C. Yen, Y. Liu, C. Lin, C. Kao, W. Wang, and Y. Hsu, "Advanced manufacturing solution to industry 4.0 trend through sensing network and Cloud Computing technologies," 2014 IEEE International Conference on Automation Science and Engineering (CASE), 2014, pp. 1150-1152, https://10.1109/CoASE.2014.6899471.

[2] J-R Jiang, “An improved cyber-physical systems architecture for Industry 4.0 smart factories," Advances in Mechanical Engineering, vol. 10, no. 6, June 2018, https://doi.org/10.1177/1687814018784192

[3] G. Kourtis, E. Kavakli, and R. Sakellariou, "A Rule-Based Approach Founded on Description Logics for Industry 4.0 Smart Factories," IEEE Transactions on Industrial Informatics, vol. 15, no. 9, pp. 48884899, Sept. 2019, https://doi.org/10.1109/TII.2019.2916622.

[4] J. Lee, B. Bagheri and H. A. Kao, "A cyber-physical systems architecture for industry 4.0-based manufacturing systems," Manufacturing Letters, 2015, vol. 3, pp. 18-23, https://doi.org/10.1016/j.mfglet.2014.12.001.

[5] A. Galletta, L. Carnevale, A. Celesti, M. Fazio, and M. Villari, "A Cloud-Based System for Improving Retention Marketing Loyalty Programs in Industry 4.0: A Study on Big Data Storage Implications," IEEE Access, vol. 6, pp. 5485-5492, 2018, https://doi.org/10.1109/ACCESS.2017.2776400.

[6] G. Aceto, V. Persico, and A. Pescapé, "A Survey on Information and Communication Technologies for Industry 4.0: State-of-the-Art, Taxonomies, Perspectives, and Challenges," IEEE Communications Surveys \& Tutorials, vol. 21, no. 4, pp. 3467-3501, 2019, https://doi.org/10.1109/COMST.2019.2938259.

[7] Z. Wang, "An Industry 4.0 approach to develop auto parameter configuration of a bottling process in a small to medium scale industry using PLC and SCADA," Procedia Manufacturing, 2019, vol. 35, pp. 725-730, https://doi.org/10.1016/j.isatra.2018.04.010. 
[8] R. Langmann and M. Stiller, "The PLC as a Smart Service in Industry 4.0 Production Systems," Appl. Sci., vol. 9, no. 18, p. 3815, 2019 https://doi.org/10.3390/app9183815.

[9] J. Mellado and F. Núñez, "Design of an IoT-PLC: A containerized programmable logical controller for the industry 4.0," Journal of Industrial Information Integration, p. 100250, Aug. 2021, https://doi.org/10.1016/j.jii.2021.100250.

[10] P. S. Bhase, G. M. Kolmare, and A. S. Deshpande, "Design \& development of energy monitoring solution," 2016 International Conference on Computing, Communication and Automation (ICCCA), 2016, pp. 1222-1227, https://doi.org/10.1109/CCAA.2016.7813928.

[11] E. Kadiyala, S. Meda, R. Basani, and S. Muthulakshmi, "Global industrial process monitoring through IoT using Raspberry Pi," 2017 International Conference on Nextgen Electronic Technologies: Silicon to Software (ICNETS2), 2017, pp. 260-262, https://doi.org/10.1109/ICNETS2.2017.8067944.

[12] J. Nikhila, "Web based Environmental Monitoring System using Raspberry Pi," 2017 International Conference on Current Trends in Computer, Electrical, Electronics and Communication (CTCEEC), 2017, pp. 1074-1080, https://doi.org/10.1109/CTCEEC.2017.8454964.

[13] P. Siagian and K. Shinoda, "Web based monitoring and control of robotic arm using Raspberry Pi," 2015 International Conference on Science in Information Technology (ICSITech), 2015, pp. 192-196, https://doi.org/10.1109/ICSITech.2015.7407802.

[14] M. Vanitha, M. Selvalakshmi and R. Selvarasu, "Monitoring and controlling of mobile robot via internet through raspberry Pi board," 2016 Second International Conference on Science Technology Engineering and Management (ICONSTEM), 2016, pp. 462-466, https://doi.org/10.1109/ICONSTEM.2016.7560864.

[15] M. S. S. Rukmini and D. Bala Gayathri Devi, "Remote control of appliances based on Raspberry Pi," 2016 Second International Conference on Cognitive Computing and Information Processing (CCIP), 2016, pp. 1-4, https://doi.org/10.1109/CCIP.2016.7802863.

[16] J. -D. Lee, W. -C. Li, J. -H. Shen and C. -W. Chuang, "Multi-robotic arms automated production line," 2018 4th International Conference on Control, Automation and Robotics (ICCAR), 2018, pp. 26-30, https://doi.org/10.1109/ICCAR.2018.8384639.

[17] N. Nadgauda and S. A. Muthukumaraswamy, "Design and Development of Industrial Automated System using PLC-SCADA," 2019 IEEE 10th GCC Conference \& Exhibition (GCC), 2019, pp. 1-6, https://doi.org/10.1109/GCC45510.2019.1570521239.

[18] S. Mohod and A. Raut, "PLC SCADA Based Fault Detection System for Steam Boiler In Remote Plant," 2019 2nd International Conference on Intelligent Computing, Instrumentation and Control Technologies (ICICICT), 2019, pp. 1007-1010, https://doi.org/10.1109/ICICICT46008.2019.8993359.

[19] R. F. Al Hinai and A. F. A. Farh, "Building Color Sensor Based on Image Processing Technology for Automatic Color Object Sorting Using PLC System," 2019 International Conference on Digitization (ICD), 2019, pp. 222-226, https://doi.org/10.1109/ICD47981.2019.9105879.

[20] R. V. Soans, G. R. Pradyumna and Y. Fukumizu, “Object Sorting using Image Processing,” $20183 r d$ IEEE International Conference on Recent Trends in Electronics, Information \& Communication Technology (RTEICT), 2018, pp. 814-818, https://doi.org/10.1109/RTEICT42901.2018.9012110.

[21] R. V. Soans, Ranjith, A. Hegde, C. Singh, and A. Kumar, "Object tracking robot using adaptive color thresholding," 2017 2nd International Conference on Communication and Electronics Systems (ICCES), 2017, pp. 790-793, https://doi.org/10.1109/CESYS.2017.8321192.

[22] V. Pereira, V. A. Fernandes, and J. Sequeira, "Low cost object sorting robotic arm using Raspberry Pi," 2014 IEEE Global Humanitarian Technology Conference - South Asia Satellite (GHTC-SAS), 2014, pp. 1-6, https://doi.org/10.1109/GHTC-SAS.2014.6967550.

[23] Huu-Quoc Nguyen, Ton Thi Kim Loan, Bui Dinh Mao and Eui-Nam Huh, "Low cost real-time system monitoring using Raspberry Pi," 2015 Seventh International Conference on Ubiquitous and Future Networks, 2015, pp. 857-859, https://doi.org/10.1109/ICUFN.2015.7182665. 
[24] S. N. Kulkarni and S. Kumar Singh, "Object Sorting Automated System using Raspberry Pi,” 2018 3rd International Conference on Communication and Electronics Systems (ICCES), 2018, pp. 217-220, https://doi.org/10.1109/CESYS.2018.8724056.

[25] F. López, F. J. Torres, V. A. Ramírez, D. A. Núñez, R. Corona and A. R. López, "Raspberry Pi for Implementation of Web Technology in an Automation Process," 2019 IEEE International Autumn Meeting on Power, Electronics and Computing (ROPEC), 2019, pp. 1-6, https://doi.org/10.1109/ROPEC48299.2019.9057040.

[26] H. R. and M. H. Safwat Hussain, "Surveillance Robot Using Raspberry Pi and IoT," 2018 International Conference on Design Innovations for 3Cs Compute Communicate Control (ICDI3C), 2018, pp. 46-51, https://doi.org/10.1109/ICDI3C.2018.00018.

[27] M. R. Mishi, R. Bibi, and T. Ahsan, "Multiple motion control system of robotic car based on IoT to produce cloud service," 2017 International Conference on Electrical, Computer and Communication Engineering (ECCE), 2017, pp. 748-751, https://doi.org/10.1109/ECACE.2017.7913002.

[28] M. A. Benmahdjoub, A. Mezouar, L. Boumediene and Y. Saidi, "Control and Monitoring of Electrical Embarked Network with Cloud Technology using Raspberry Pi," 2018 International Conference on Electrical Sciences and Technologies in Maghreb (CISTEM), 2018, pp. 1-6, https://doi.org/10.1109/CISTEM.2018.8613586.

[29] C. Kaymak and A. Ucar, "Implementation of Object Detection and Recognition Algorithms on a Robotic Arm Platform Using Raspberry Pi," 2018 International Conference on Artificial Intelligence and Data Processing (IDAP), 2018, pp. 1-8, https://doi.org/10.1109/IDAP.2018.8620916.

[30] B. V. Santhosh Krishna, J. Oviya, S. Gowri, and M. Varshini, "Cloud robotics in industry using Raspberry Pi," 2016 Second International Conference on Science Technology Engineering and Management (ICONSTEM), 2016, pp. 543-547, https://doi.org/10.1109/ICONSTEM.2016.7560952. 